\title{
Stationary Computer Based Voting Process at Polling Booth
}

\author{
Vetrivel.D.S.B \\ Electronics and \\ Communication Engineering, \\ PSNA College of Engineering \\ and Technology \\ Dindigul, India
}

\author{
Niranjan Ravi \\ Electronics and \\ Communication Engineering, \\ PSNA College of Engineering \\ and Technology \\ Dindigul, India
}

\author{
Vishal Sundarrajan \\ Electronics and \\ Communication Engineering, \\ PSNA College of Engineering \\ and Technology \\ Dindigul, India
}

\begin{abstract}
System based voting is capable of saving considerable printing stationery and transport of large volumes of electoral material. It is easy to transport, store, and maintain. It completely rules out the chance of invalid votes. Its use results in reduction of polling time, resulting in fewer problems in electoral preparations, law and order, candidates' expenditure, etc. easy and accurate counting without any mischief at the counting centre. Though all these can be done by Electronic Voting Machine (EVMs), there are still some disadvantages that can be overcome by the use of computer providing the same level of security maintenance, distribution and sharing of votes in the polling booth. Since the computer can ease the addition process by processing it internally in CPU when executing the codes, it is also possible to extend the memory allocation and quick processing for the prompt publishing of results. Following the recent advancement in touch technology, it is possible for a voter to directly interact with the computer.
\end{abstract}

Keywords: EVMs, Database, VB.NET, Polling booth, LAN connected computers.

\section{INTRODUCTION}

EVMs in INDIA an Electronic Voting Machine consists of two Units - a Control Unit and a Balloting Unit - joined by a five-meter cable. The Control Unit is with the Presiding Officer or a Polling Officer and the Balloting Unit is placed inside the voting compartment. Instead of issuing a ballot paper, the Polling Officer in-charge of the Control Unit will press the Ballot Button. This will enable the voter to cast his vote by pressing the blue button on the Balloting Unit against the candidate and symbol of his choice. EVMs can record a maximum of 3840 votes. EVMs can cater to a maximum of 64 candidates. There is provision for 16 candidates in a Balloting Unit. If the total number of candidates exceeds 16 , a second Balloting Unit can be linked parallel to the first Balloting Unit. Similarly, if the total number of candidates exceeds 32, a third Balloting Unit can be attached and if the total number of candidates exceeds 48, a fourth Balloting Unit can be attached to cater to a maximum of 64 candidates. In case the number of contesting candidates goes beyond 64 in any constituency, EVMs cannot be used in such a constituency.

The conventional method of voting by means of ballot box and ballot paper will have to be adopted in such a constituency. In case of miscreants, EVMs allow them to record five votes per minute. The normal rule is to count the votes polling station-wise and this is what is being done when EVM is used in each polling station. The mixing system of counting is done only in those constituencies specially notified by the Election Commission. Even in such cases, the result from each EVM can be fed into a Master Counting Machine in which case, only the total result of an Assembly Constituency will be known and not the result in each individual polling station. [1]

It is clear from the above that polling officer need to manually operate or pass it to the Master Counting Machine. This however is not required in case of computer as it is intrinsic in CPU and it does not allow any voter to record more than one vote at a time once the authentication is given to a particular voter by polling officer. The only disadvantage of computer voting system is the power consumption while other features are almost the same compared to the former.

Though there are other high level languages available for efficient programming, we have designed using VB.net, an object-oriented computer programming language that can be viewed as an evolution of the classic Visual Basic (VB), implemented on the .NET Framework. Microsoft currently supplies two main editions of IDEs for developing in Visual Basic: Microsoft Visual Studio 2012, with a backhand database maintained by MS Access.[2]

Two or more computers can be connected for parallel processing through LAN connection. New applications being developed are often designed so that they can transfer data securely across insecure networks. i.e. some type of authentication or encryption is built-in IP level encryption (for TCP/IP networks) offers a secure channel between two machines, even over insecure networks. [3]

\section{RELATED WORKS}

Democratic countries like India, US deploy electronic voting system. India uses EVMs (Electronic Voting Machines) as discussed in the introduction passage. Though it is highly secured the problems surrounding the voting machine can cause potential vulnerabilities. One demonstration attack was based on replacing the part inside the control unit that actually displays the candidates' vote totals. The study showed how a substitute, "dishonest" part could output fraudulent election results. This component can be programmed to steal a percentage of the votes in favor of a chosen candidate. The second demonstration attack used a small clip-on device to manipulate the vote storage memory inside the machine.

Votes stored in the EVM between the election and the public counting session can be changed by using a specially made pocket-sized device. When you open the machine, you find micro-controllers, under which are electrically enabled programs, with 'read-only' memory. It is used only for storage. However, you can read and write memory from an external interface. The researchers developed a small clip with a chip on the top to read votes inside the memory and manipulate the data by swapping the vote from one candidate to another. In 
order to mitigate these threats, the researchers suggest moving to a voting system that provides greater transparency, such as paper ballots, precinct count optical scan, or a voter verified paper audit trail, since, in any of these systems, skeptical voters could, in principle, observe the physical counting process to gain confidence that the outcome is fair. [4] However, these problems can easily be eliminated by the use of Computer programming.

\section{MODULES DESCRIPTION}

\subsection{Verification and Authentication}

Here the authentication is provided by checking the details of the voter as it is already maintained in the database. The details must be valid for recording the vote for a particular Candidate.(In the current voting system, the details are verified by a human evaluator). Once the access is given for a voter by the polling officer he can vote only once for a particular candidate. Once the party has been chosen the window asks for confirmation. By confirming, the voter can be displayed a message 'Your vote has been Recorded'. Alternative signals like beep sound light can also be made possible by the use of proper coding.

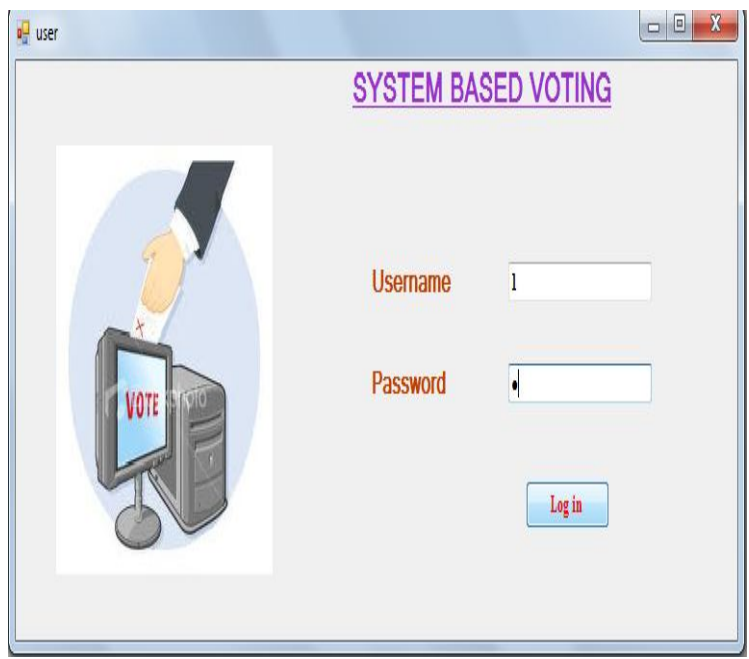

Figure. 1 Example of an Authentication form

\subsection{Counting Process}

The counting of votes can be done simultaneously when each voter record his/her vote. The window showed the symbol with the name of the party where the voter should select his/her candidate by the use of radio button before pressing the vote button to record their vote. By clicking on the vote button, the confirmation form will display 'YOU HAVE VOTED FOR ...' The voting is highly secured because no other peers or even the electoral officer can come to know whom a particular voter voted for. Since the counting is done real-time by computer the result can be unveiled immediately after the elections. This saves more time as it all happens inside a single electronic component, computer. No need to feed the accumulated data to Master EVMs. [7]

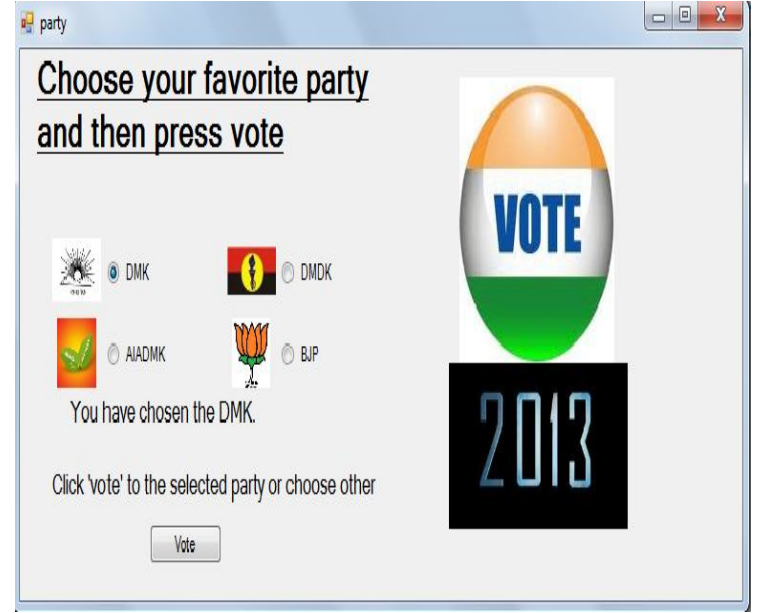

Figure. 2 Example of a Voting form

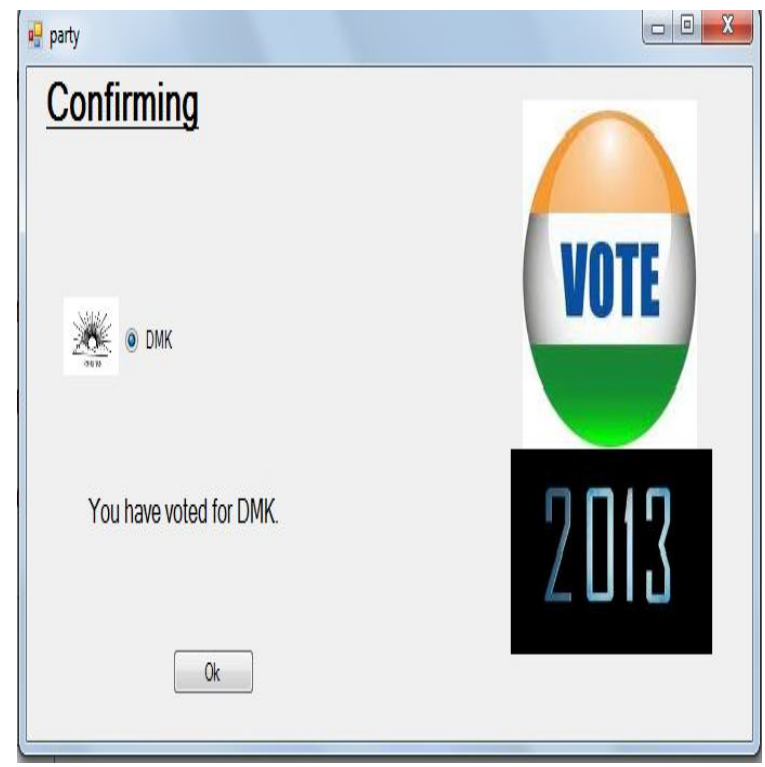

Figure. 3 Example of a Confirmation form

\subsection{Database Maintenance}

The database should store all the details of the voter. Efficient database software such as Big Data, MySQL, IBM DB2,ORACLE can be used for fast searching process. Public key fingerprint or digital verification can also help for the verification of details. This way of connecting to a DB provides a highly secured and there would be no chance of any miscreants.

\subsection{Displaying Results}

The result form is made to hide from the voter and candidature in the same way as giving authentication to a particular voter. Only the higher officials from the election commission should know the password and by the time of counting the corresponding password from each ward is typed to see the results. In the previous system, the button is sealed and total number of votes is calculated by pressing the 'Total' button. 


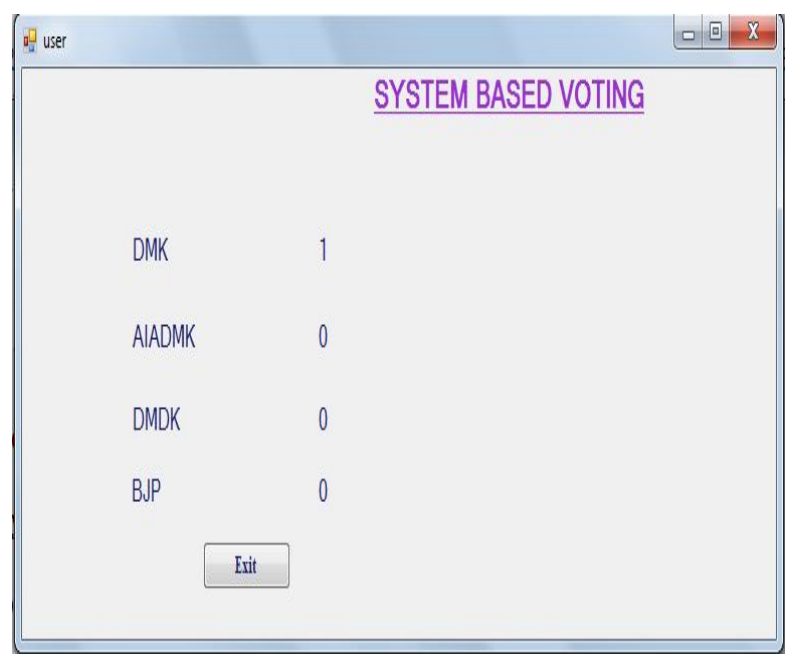

Figure. 4 Example of a Results form

\section{PROPOSED ALGORITHM 4.1 Voting Process}

1. The voter will be checked for their details.

2. After verification, the legal voter will be provided authentication to vote for his candidate.

3. The voter should select his/her candidate by choose radio button option and press on vote button.

4. A confirmation page will ask for confirmation. After confirming, his vote will be recorded.

5. The computer will once again ask for officer authentication for next voter and the process repeats.

\subsection{Counting Process}

1. Higher officials will be given credentials to access the form.

2. By typing the credentials, the results of election for each ward will be displayed. (It is also possible to calculate results in individual polling station)

\section{ADVANTAGES}

\subsection{Vulnerability to hacking}

If there is no external communications pathway, then there is no risk of hacking, or gaining unauthorized entry into the tabulation system. Since we are not dealing with any modem transfer it is practically impossible to hack the independent computer. [9]

\subsection{Disabled Voters and Computer based Voting}

Touchscreens are the only system which allows a voter with a disability to cast a secret and independent vote. The audio ballot and adaptive aids, such as sip and puff and jelly switches, make it possible for all of these citizens to cast a secret and independent ballot. [10]

\subsection{Accuracy in Capturing Voters' Intent}

The advantages of DRE systems include: no 'chad'; eliminating the possibility of an 'over vote' (or making more selections than permissible) and advising the voter of any 'under vote' (when a voter makes fewer than the maximum number of permissible selections in a contest).Because the confirmation page asks for the final decision the voter is less likely to make a mistake the second time.

\subsection{Secure storage of cast votes}

Concerns about security of the collection and counting process have always been important. Computers offer the first technology that can easily make copies of information in different forms for archival preservation. [11]

\subsection{Malicious Software Programming}

The concern that unscrupulous programmers will try to rig elections through deceptive software has led to specific processes and policies to avoid such an event. For example, software code passes through numerous internal and external checks before use in an actual election, including rigorous certification testing by independent certification bodies. Voting system software is engineered months in advance of actual elections, making it very unlikely for programmers to know who candidates will be and impossible to know how their names will appear on ballots. The source code is held in escrow by various state and federal officials, and local officials do not have access to it, thus preventing code changes at the local level.

\subsection{Physical security of machines}

Attempts to tamper with terminals, via privacy security screen removal and unlocking of bay doors, would be quickly noticed by the diligent, trained Election Judge and others in the polling place.

\section{CONCLUSION}

Doing such social projects should be favourable to people. Since the people who are not aware of the technology should be taught. In the above mentioned system there would be nothing other than selecting the candidate and confirmation button. Since the voting is being carried out in the polling booth there would be no chance of invading of hacker as each machine works independently providing its own backup. In 
case of goes out of order, EVMs can be switched to be connected in parallel or replaced with spare EVMs. Another advantage is that it reduces the works of presiding officer in that particular polling booth because human beings are always prone to mistakes. The main confession of using this system is that it cannot be used in the places where there is no power supply. Since EVMs work on a $6 \mathrm{~V}$ battery it is possible to use even in the places with no power connections. But Developing countries like India should consider such technology by looking at the future.

\section{REFERENCES}

[1] Bellis, M. (2011). The History of Voting Machines. www.about.com. Retrieved 25th October, 2011.

[2] Buchsbaum, T. (2004). "E-voting: International developments and lessons learnt". Proceedings of Electronic Voting in Europe Technology, Law, Politics and Society

[3] Friel, B., (2006) Let the Recounts Begin, National Journal Government Accountability Office (May 2004) "Electronic Voting Offers Opportunities and Presents Challenges" Tavel, P. 2007 Modeling and Simulation Design. AK Peters Ltd.

[4] Rubin, A.D., (2002) "Security considerations for remote electronic voting", Communications of the ACM, 45(12): 39-44, December 2002.

[5] INDIAN VOTING MACHINES reference from Wikipedia http://en.wikipedia.org/wiki/Indian_voting_machine

[6] Daniel Barrett, Richard Silverman, Robert Byrnes - 2003 books.google.co.in/books?isbn $=0596003919$

[7] Official website of Election commission of India http://eci.nic.in/eci main1/evm.aspx

[8] Visual Basic.Net:The Complete Reference by Shapiro2002

books.google.co.in/books?isbn=0070495114

[9] Dana DeBeauvoir Elections Administrator and County Clerk, TravisCounty, Texas

"Prevention of Attack, Not Detection After the Fact," submitted as an appendix to testimony before the U.S. Election Assistance Commission may5,2004

[10] JimDickson, Vice President, American Association of People with Disabilities. Testimony before the U.S. Election Assistance Commission may 5,2004

[11] TedSelker,PhDDirector, Caltech/MIT Voting Technology Project "Security Vulnerabilities and Problems with VVPT," Caltech/MIT Voting Technology Project Working Paper 13 Apr. 2004 